\title{
Retraction Note to: All-Atom Molecular-Level Analysis of the Ballistic-Impact-Induced Densification and Devitrification of Fused Silica
}

\author{
M. Grujicic, J.S. Snipes, S. Ramaswami, R. Yavari, and R.S. Barsoum
}

Retraction Note to: JMEPEG (2015) 24:2970-2983

DOI: 10.1007/s11665-015-1590-2

The Publisher has retracted the following article from the Journal of Materials Engineering and Performance at the request of the Editor-in-Chief, following an investigation that revealed extensive duplication of previous publications.

M. Grujicic, J.S. Snipes, S. Ramaswami, R. Yavari and R.S. Barsoum, "All-Atom Molecular-Level Analysis of the Ballistic-
Impact-Induced Densification and Devitrification of Fused Silica”, J. Mater. Eng. Perform. (2015), 24, 2970.

The above article is a copy of M. Grujicic, J.S. Snipes, S. Ramaswami, R. Yavari and B. Cheeseman, "Densification and Devitrification of Fused Silica Induced by Ballistic Impact: A Computational Investigation", J. Nanomater. (2015), Article ID 650625, DOI:10.1155/2015/650625.

We regret the inconvenience caused to our readers.

M. Grujicic: Deceased.

The online version of the original article can be found under doi: 10.1007/s11665-015-1590-2.

M. Grujicic, J.S. Snipes, S. Ramaswami, and R. Yavari, Department of Mechanical Engineering, Clemson University, 241 Engineering Innovation Building, Clemson, SC 29634-0921; and R.S. Barsoum, Ships and Engineering Systems Division, Office of Naval Research, Arlington, VA 22203. Contact e-mail: gmica@clemson.edu. 